\section{Modelos de assistência ao indivíduo com obesidade na atenção básica em saúde no Estado do Rio de Janeiro, Brasil}

\author{
Models of care for individuals with obesity in \\ primary healthcare in the state of \\ Rio de Janeiro, Brazil
}

\section{Modelos de asistencia al individuo con obesidad en la atención básica de salud en el Estado de Río de Janeiro}

\author{
Luciene Burlandy 1 \\ Márcia Regina Mazalotti Teixeira 2 \\ Luciana Maria Cerqueira Castro 3 \\ Myrian Coelho Cunha Cruz 4 \\ Claudia Roberta Bocca Santos 5 \\ Simone Raimondi de Souza 6 \\ Luziene Simões Benchimol 1 \\ Thays da Silva Araújo 1 \\ Doralice Batista das Neves Ramos 1 \\ Thamillys Rodrigues Souza 1
}

doi: 10.1590/0102-311X00093419

\section{Resumo}

O Brasil vem instituindo políticas de prevenção e controle da obesidade por meio do Sistema Único de Saúde, e o estudo analisou as características dos "modelos assistenciais" propostos e referidos por profissionais da atenção básica no Estado do Rio de Janeiro. Os métodos incluíram entrevistas e grupos focais com profissionais e gestores da atenção básica e das Áreas Técnicas de Alimentação e Nutrição (ATAN) dos 92 municípios do Rio de Janeiro, e análise documental de normativas federais e estaduais. A análise foi norteada pelas dimensões organizativa e técnico assistencial, e considerou os princípios da atenção integral em saúde. Os principais desafios referidos pelos profissionais estão relacionados com: a adesão aos processos terapêuticos e consequente sentimento de frustração e impotência; a atuação em equipe multiprofissional; $e$ a constatação de despreparo para lidar com a complexidade do processo saúde/doença relacionado com a obesidade. Alguns princípios e diretrizes pautados nos documentos de politicas governamentais são estratégicos para enfrentar esses desafios, especialmente: a corresponsabilização entre profissional e usuário, pois pode contribuir para evitar os extremos da culpabilização el ou vitimização; a valorização de outros ganhos para além da perda de peso, que pode ressignificar a concepção de adesão ao tratamento; a atuação multiprofissional para que se desenvolva uma compreensão contextualizada do processo saúde/doença e seus múltiplos condicionantes, e para que os profissionais consigam lidar com os seus próprios sentimentos e estigmas em relação à pessoa com obesidade.

Atenção Primária à Saúde; Obesidade; Assistência à Saúde; Integralidade em Saúde

\author{
Correspondência \\ L. Burlandy \\ Faculdade de Nutrição, Universidade Federal Fluminense. \\ Rua São Paulo 30, 4o andar, Rio de Janeiro, RJ \\ 24015-110, Brasil. \\ burlandy@uol.com.br \\ 1 Faculdade de Nutrição, Universidade Federal Fluminense, \\ Niterói, Brasil. \\ 2 Secretaria de Estado de Saúde do Rio de Janeiro, Rio de \\ Janeiro, Brasil. \\ 3 Instituto de Nutrição, Universidade do Estado do Rio de \\ Janeiro, Rio de Janeiro, Brasil. \\ 4 Fundação Municipal de Saúde de Niterói, Niterói, Brasil. \\ 5 Escola de Nutrição, Universidade Federal do Estado do Rio de \\ Janeiro, Rio de Janeiro, Brasil. \\ 6 Instituto Estadual de Cardiologia Aloysio de Castro, Rio de \\ Janeiro, Brasil.
}




\section{Introdução}

A obesidade é considerada uma prioridade global de saúde pública por sua magnitude e relação com doenças crônicas. Em 2013, atingiu 20\% dos adultos brasileiros, sendo 56,9\% com sobrepeso 1 e, embora políticas nacionais tenham sido instituídas 2 , trata-se de um cenário de difícil reversão e que demanda articular o cuidado individual com ações que afetem o ambiente obesogênico 3,4. Além disso, a baixa efetividade das intervenções individuais pautadas em "modelos assistenciais" biologicistas e curativos impõe reflexões sobre os caminhos para a inovação das práticas de cuidado 5,6.

O conceito de "modelo assistencial" vem sendo problematizado desde a década de 1970, quando emergiram as críticas ao denominado "modelo biomédico". A instituição do Sistema Único de Saúde (SUS) em 1990 impulsionou a reorientação desse modelo na direção da atenção integral à saúde, culminando com a consolidação da Estratégia Saúde da Família (ESF). Além disso, a ótica da promoção da saúde reforçou novas concepções sobre cuidado ao propor ações positivas de saúde, considerando os múltiplos condicionantes do processo saúde/doença 5,7 .

O debate sobre modelos assistenciais abarca elementos-chave como as formas de organização das relações entre profissionais e usuários, saberes e técnicas utilizadas para atender as necessidades em saúde, práticas e processos de trabalho 7 . A reorientação dos modelos vigentes é um processo complexo que implica mudanças em distintas dimensões, tais como: (1) gerencial - referente aos mecanismos de condução do processo de reorganização das ações e dos serviços; (2) organizativa - referente ao estabelecimento das relações entre as unidades de prestação de serviços, considerando os níveis de complexidade tecnológica do processo de produção do cuidado; e (3) técnico assistencial, ou operativa, referente às relações que se estabelecem entre o(s) sujeito(s) das práticas e seus objetos de trabalho em vários planos (promoção da saúde, prevenção de riscos e agravos, e recuperação e reabilitação) 7 .

A ESF distingue-se do modelo biomédico por ser fundamentada na integralidade; na construção de Redes de Atenção à Saúde (RAS), tendo a atenção básica como articuladora dos demais níveis por meio dos mecanismos de referência e contrarreferência; na articulação entre promoção da saúde, prevenção, tratamento e reabilitação; no foco na família, grupos e comunidades; na compreensão dos condicionantes históricos, sociais, culturais do processo saúde/doença; nas relações acolhedoras, de vínculo, compromisso e corresponsabilidade entre os profissionais de saúde, gestores e população; e na equipe multiprofissional 5,7. Tais características estão relacionadas com as dimensões "organizativa" e "técnico assistencial" de reorientação dos modelos assistenciais, incluindo as "práticas de cuidado" 8 .

A problematização dos desafios para a reorientação desses modelos demanda considerar os princípios que fundamentam tais práticas e as tensões existentes, especialmente em relação ao caráter mais ou menos medicalizante e à imposição da racionalidade médica por meio do foco na responsabilização individual e no manejo comportamental de "riscos". Isso pode ocorrer mesmo no âmbito da promoção da saúde, que surge como possibilidade de reorientação do "modelo biomédico", mas, historicamente, assume diferentes vertentes como a "socioambiental" - centrada na consolidação de contextos de vida saudáveis com base em uma visão positiva da saúde - que oferece um contraponto à vertente medicalizante 9 .

Dias et al. 2 problematizaram como essas duas grandes vertentes de promoção da saúde pautaram políticas de prevenção e controle da obesidade no Brasil. Considerando que tais políticas simultaneamente expressam e norteiam a atuação dos profissionais de saúde, o presente estudo analisou as características dos modelos assistenciais que fundamentam as ações de prevenção e controle da obesidade propostas nas políticas do SUS, e referidas por profissionais que atuam na atenção básica, em municípios do Estado do Rio de Janeiro nas dimensões: (1) organizativa, visando a identificar princípios e diretrizes gerais para a organização institucional; e (2) técnico assistencial, visando a identificar desafios para o cuidado integral em saúde 7 . 


\section{Métodos}

O estudo é parte de um projeto que analisou as ações de prevenção e controle da obesidade nos 92 municípios do Estado do Rio de Janeiro no âmbito da atenção básica, entre 2014 e 2018, com base nos métodos de: (1) análise documental de políticas governamentais; (2) entrevistas semiestruturadas presenciais com apoiadores regionais da atenção básica, referências regionais/municipais das Áreas Técnicas de Alimentação e Nutrição (ATAN) e pacientes do Instituto Estadual de Cardiologia Aloysio de Castro em acompanhamento nutricional de sobrepeso e obesidade; (3) grupos focais com referências municipais da ATAN, interlocutores da vigilância de doenças crônicas das diferentes regiões de saúde do Estado do Rio de Janeiro, apoiadores regionais da atenção básica; (4) aplicação de formulário online (FormSUS - http://formsus.datasus.gov.br/site/default.php), com referências municipais de ATAN; e (5) entrevistas telefônicas com referências municipais da ATAN (Quadro 1). As narrativas e os depoimentos foram obtidos por meio desses diferentes instrumentos de coleta de dados que, considerando as especificidades dos depoentes, abordaram questões sobre: as ações de prevenção e controle da obesidade; desafios e estratégias para a implementação. O projeto foi submetido e aprovado pelo Comitê de Ética do Hospital Antônio Pedro - parecer CEP 508.687 de 9 de janeiro de 2014 - CAE 22822413.0.0000.5243.

O artigo apresenta a análise dos "modelos assistenciais" propostos nos documentos de políticas e referidos pelos depoentes. Baseou-se em referencial analítico que considera que a reorientação dos modelos vigentes na perspectiva da integralidade do cuidado demanda inovações nos âmbitos organizativo e técnico assistencial da atenção à saúde, que abarcam a organização da atenção à saúde, das

\section{Quadro 1}

Quadro síntese dos métodos de construção dos dados para análise dos modelos de assistência ao indivíduo com obesidade na atenção básica em saúde no Estado do Rio de Janeiro, Brasil, 2014-2018.

\begin{tabular}{|c|c|c|c|}
\hline & & Dados primários & Dados secundários \\
\hline \multirow[t]{4}{*}{$\begin{array}{l}\text { 1a etapa } \\
(2014-2016) \\
101 \text { depoi- } \\
\text { mentos }\end{array}$} & $\begin{array}{c}\text { Entrevistas } \\
\text { semiestruturadas }\end{array}$ & $\begin{array}{l}\text { - } 5 \text { entrevistas com apoiadores regionais da atenção básica; } \\
-8 \text { entrevistas com referências regionais da ATAN; } \\
\text { - } 1 \text { referência de ATAN de município que iniciou processo de implementação } \\
\text { de ações de prevenção e controle da obesidade na perspectiva da RAS. }\end{array}$ & \multirow[t]{4}{*}{$\begin{array}{l}\text { Análise documental } \\
\text { de políticas nacionais, } \\
\text { estaduais e municipais. }\end{array}$} \\
\hline & Grupos focais & $\begin{array}{l}55 \text { participantes, incluindo: } \\
\text { - Referências municipais da ATAN; } \\
\text { - Profissionais de saúde de nove regiões de saúde do estado. }\end{array}$ & \\
\hline & $\begin{array}{c}\text { Formulário } \\
\text { Formsus }\end{array}$ & - 16 referências municipais da ATAN. & \\
\hline & $\begin{array}{l}\text { Entrevistas } \\
\text { telefônicas }\end{array}$ & - 20 referências municipais da ATAN. & \\
\hline \multirow{3}{*}{$\begin{array}{l}\text { 2a etapa } \\
(2016-2018)\end{array}$} & Roda de conversa & - Integrantes da ATAN estadual. & \multirow{3}{*}{$\begin{array}{l}\text { Análise documental } \\
\text { de políticas nacionais, } \\
\text { estaduais e municipais. }\end{array}$} \\
\hline & Grupos focais & $\begin{array}{l}\text { - } 8 \text { apoiadores regionais da Atenção Básica; } \\
\text { - } 3 \text { grupos focais com Interlocutores da Vigilância de Doenças Crônicas da } \\
\text { Secretaria de Estado da Saúde do Rio de Janeiro (28 participantes). }\end{array}$ & \\
\hline & Entrevistas & $\begin{array}{l}\text { - } 2 \text { referências de ATAN de municípios em processo de construção de ações } \\
\text { de prevenção e controle da obesidade na perspectiva da RAS; } \\
\text { - } 25 \text { pacientes do Instituto Estadual de Cardiologia Aloysio de Castro (IECAC). }\end{array}$ & \\
\hline
\end{tabular}


práticas e dos modos de prestar cuidados 5,7. Para identificar elementos empíricos relacionados com esses três componentes, os dados provenientes das diferentes fontes de pesquisa (documentos, entrevistas, grupos focais) foram abordados de forma integrada baseando-se nas seguintes dimensões de análise: (1) as propostas de organização institucional da atenção à saúde presentes nos documentos de políticas, considerando que apresentam diretrizes e princípios norteadores das práticas; (2) as práticas de atenção propostas nesses documentos e relatadas pelos depoentes; (3) os princípios e diretrizes que fundamentam a organização institucional e as práticas de atenção à saúde propostos e que orientam os modos de prestar cuidados. Para cada dimensão de análise foram identificados no material discursivo, proveniente dos documentos e dos relatos obtidos nas entrevistas e grupos focais, temas centrais e categorias-chave (Quadro 2). A análise também considerou as características indicadas na literatura acadêmica que distinguem as principais vertentes de modelos assistenciais: o modelo biomédico e a ESF em diálogo com as vertentes da promoção da saúde 5,9 .

Com base no mapeamento de documentos do governo federal que tratam a obesidade como questão de política pública 2, foram identificados e selecionados aqueles que subsidiam a organização, as práticas e a prestação de cuidados ao indivíduo com obesidade no âmbito do SUS, situados em dois grandes grupos: as Portarias Governamentais que instituem macro diretrizes referentes às RAS e a linha de cuidado da obesidade; os documentos de subsídio aos profissionais da atenção básica no cuidado à pessoa com obesidade e com doenças crônicas (Quadro 2).

\section{Resultados}

\section{As propostas de organização da atenção à saúde}

As propostas governamentais de organização da atenção à saúde no SUS são norteadas pelo objetivo de consolidação das RAS a partir de um processo de gestão da clínica, visando a ampliar seu objeto de trabalho para além da doença. "A 'clínica do sujeito' é a principal perspectiva de ampliação da clínica no sentido de promover a autonomia dos usuários e a decisão compartilhada do processo terapêutico" 10 (p. 6).

As RAS das pessoas com doenças crônicas foram instituídas como estratégias para fomentar a mudança no modelo assistencial por meio da qualificação da atenção integral à saúde, visando a superar a fragmentação da atenção e da gestão à saúde 11. As RAS pressupõem que o modelo assistencial vigente é insuficiente e que a tendência de declínio dos problemas agudos de saúde e ascensão das doenças crônicas demandam sua adequação com base nos seguintes princípios e diretrizes: integralidade; humanização; cuidado multiprofissional; corresponsabilização profissional/usuário; construção do vínculo, da autonomia e do autocuidado do usuário. Reconhecem de forma singular os determinantes sociais de saúde e as estratégias intersetoriais e participativas de promoção da saúde e prevenção de doenças, as equipes multiprofissionais, bem como o respeito às diversidades étnico-raciais, sociais e religiosas, aos hábitos e culturas locais 11.

Dentre as tecnologias previstas para a gestão da clínica, "as Linhas de Cuidado são estabelecidas como forma de articulação de recursos e das práticas entre as unidades de atenção de uma dada região de saúde" 11 (p. 5), sendo a ESF o principal modelo assistencial para a organização da atenção básica 10. A organização da prevenção e tratamento do sobrepeso e obesidade foi instituída como linhas de cuidado prioritária da RAS das pessoas com doenças crônicas por meio da linha de cuidado da obesidade, que estabelece normas e critérios para a construção de fluxos de atendimento integral, definição de mecanismos de comunicação e competências de cada ponto de atenção, segundo os princípios da universalidade, equidade, regionalização, hierarquização e integralidade 11,12,13,14,15. Esses princípios fundamentam as propostas apresentadas nos documentos de subsídio aos profissionais da atenção básica e cabe problematizá-las em diálogo com os relatos dos depoentes (Quadro 2). 
Quadro 2

Quadro síntese das fontes de pesquisa e elementos empíricos identificados segundo as dimensões de análise dos modelos de assistência ao indivíduo com obesidade na atenção básica em saúde no Estado do Rio de Janeiro, Brasil, 2014-2018.

\begin{tabular}{|c|c|c|c|}
\hline FONTES & \multicolumn{3}{|c|}{ DIMENSÕES DE ANÁLISE } \\
\hline $\begin{array}{l}\text { Documentos } \\
\text { analisados }\end{array}$ & Organização institucional & Práticas de atenção à saúde & Princípios e diretrizes \\
\hline $\begin{array}{l}\text { Cadernos de Atenção } \\
\text { Básica } 1216 . \\
\text { Documento que } \\
\text { aborda a compreensão } \\
\text { da obesidade e } \\
\text { seus condicionantes } \\
\text { e as atribuições } \\
\text { dos profissionais, } \\
\text { principalmente da } \\
\text { atenção básica. }\end{array}$ & $\begin{array}{l}\text { Organização da atenção na prevenção e } \\
\text { acompanhamento da obesidade: critérios } \\
\text { para referência e contrarreferência no SUS, } \\
\text { com base no IMC; estabelecimento do fluxo } \\
\text { de atenção para prevenção, tratamento e } \\
\text { acompanhamento da obesidade nos níveis de } \\
\text { complexidade no SUS. }\end{array}$ & $\begin{array}{c}\text { A abordagem integral do usuário } \\
\text { demanda considerar o contexto } \\
\text { familiar e social, aspectos psicológicos, } \\
\text { afetivos, simbólicos, culturais, históricos } \\
\text { e ecológicos da alimentação; atuar de } \\
\text { forma integrada à vigilância em saúde, } \\
\text { identificar situações de risco associadas } \\
\text { ao sobrepeso/obesidade. } \\
\text { Terapêutica singular considerando } \\
\text { as especificidades de cada caso e as } \\
\text { relações com as condições de vida e o } \\
\text { ambiente (político, social, econômico, } \\
\text { cultural e físico). } \\
\text { Apropriação do corpo e do } \\
\text { autocuidado. } \\
\text { Resgate da culinária como parte do } \\
\text { processo terapêutico. }\end{array}$ & $\begin{array}{c}\text { Alimentação saudável } \\
\text { como direito; } \\
\text { Intersetorialidade; } \\
\text { Equidade; } \\
\text { Desenvolvimento humano } \\
\text { e social; } \\
\text { Diversidade; } \\
\text { Qualidade de vida; } \\
\text { Regionalização; } \\
\text { Integralidade no cuidado } \\
\text { em saúde; } \\
\text { Resolutibilidade da } \\
\text { Atenção; } \\
\text { Humanização; } \\
\text { Corresponsabilização do } \\
\text { cuidado e autocuidado; } \\
\text { Construção de vínculo nas } \\
\text { práticas de atenção. }\end{array}$ \\
\hline $\begin{array}{l}\text { Plano de ações } \\
\text { Estratégicas de } \\
\text { Enfrentamento das } \\
\text { DCNT no Estado do } \\
\text { Rio de Janeiro, } \\
2013-202233 \text {. } \\
\text { Apresenta ações, } \\
\text { respectivos } \\
\text { responsáveis, } \\
\text { metas, indicadores e } \\
\text { resultados esperados } \\
\text { em relação ao } \\
\text { enfrentamento de } \\
\text { DCNT no Estado do Rio } \\
\text { de Janeiro. }\end{array}$ & $\begin{array}{l}\text { Promover e fortalecer parcerias intra } \\
\text { e intersetoriais no estado e municípios } \\
\text { para o enfrentamento dos determinantes } \\
\text { socioambientais das DCNT e de promoção de } \\
\text { comportamentos saudáveis; } \\
\text { Importância da integração dos diferentes } \\
\text { setores da saúde que lidam com as prioridades } \\
\text { da Política Nacional de Promoção da Saúde e } \\
\text { prevenção de DCNT, dentre elas a alimentação } \\
\text { e nutrição; } \\
\text { Desenvolver e articular ações para prevenção } \\
\text { e controle da obesidade, em cumprimento ao } \\
\text { Plano Nacional de Prevenção e Controle da } \\
\text { Obesidade; } \\
\text { Implementar e qualificar a vigilância alimentar } \\
\text { e nutricional no contexto da atenção básica } \\
\text { por meio da utilização do SISVAN Web, } \\
\text { em todas as fases do ciclo de vida, a fim } \\
\text { de monitorar a prevalência de sobrepeso, } \\
\text { obesidade e fatores associados ao consumo de } \\
\text { alimentos não saudáveis. }\end{array}$ & $\begin{array}{c}\text { Terapêutica multiprofissional } \\
\text { desenvolvida por meio de equipe } \\
\text { multidisciplinar. } \\
\text { Importância de considerar os } \\
\text { determinantes e condicionantes sociais } \\
\text { e a transversalidade das açães que } \\
\text { perpassam todos os níveis de atenção. } \\
\text { Estimular e apoiar os modelos de } \\
\text { atenção integral à saúde do portador } \\
\text { de excesso de peso na rede de saúde, } \\
\text { em especial na atenção básica. }\end{array}$ & $\begin{array}{l}\text { Intersetorialidade; } \\
\text { Equidade; } \\
\text { Atenção integral à saúde; } \\
\text { Vínculo ao cuidador e à } \\
\text { equipe de saúde. }\end{array}$ \\
\hline
\end{tabular}

(continua) 
Quadro 2 (continuação)

\begin{tabular}{|c|c|c|c|}
\hline FONTES & \multicolumn{3}{|c|}{ DIMENSÕES DE ANÁLISE } \\
\hline $\begin{array}{l}\text { Documentos } \\
\text { analisados }\end{array}$ & Organização institucional & Práticas de atenção à saúde & Princípios e diretrizes \\
\hline $\begin{array}{l}\text { Portaria no } 424 \text {, de } 19 \\
\text { de março de } 201312 . \\
\text { Redefine as diretrizes } \\
\text { para a organização } \\
\text { da prevenção e } \\
\text { do tratamento do } \\
\text { sobrepeso e obesidade } \\
\text { como linha de cuidado } \\
\text { prioritária da RAS das } \\
\text { pessoas com DCNT. }\end{array}$ & $\begin{array}{l}\text { Organização da oferta integral de cuidados na } \\
\text { RAS por meio da definição de competências de } \\
\text { cada ponto de atenção, do estabelecimento de } \\
\text { mecanismos de comunicação entre eles, bem } \\
\text { como da garantia dos recursos necessários ao } \\
\text { seu funcionamento segundo o planejamento } \\
\text { de cada ente federativo e os princípios e } \\
\text { diretrizes de universalidade, equidade, } \\
\text { regionalização, hierarquização e integralidade } \\
\text { da atenção à saúde; } \\
\text { Articulação de ações intersetoriais para } \\
\text { promoção da saúde, de forma a apoiar os } \\
\text { indivíduos, famílias e comunidades na adoção } \\
\text { de modos de vida saudáveis que permitam a } \\
\text { manutenção ou recuperação do } \\
\text { peso saudável; } \\
\text { Elaboração de planos regionais para } \\
\text { organização da linha de cuidado da obesidade. }\end{array}$ & $\begin{array}{c}\text { Apoio diagnóstico e terapêutico } \\
\text { adequado para tratamento do } \\
\text { sobrepeso e da obesidade, com } \\
\text { efetivação de um modelo centrado } \\
\text { no usuário, baseado nas suas } \\
\text { necessidades de saúde, respeitando as } \\
\text { diversidades étnico-raciais, culturais, } \\
\text { sociais e religiosas; e garantia da } \\
\text { oferta de práticas integrativas e } \\
\text { complementares para promoção } \\
\text { da saúde, prevenção de agravos e } \\
\text { tratamento das pessoas com sobrepeso } \\
\text { e obesidade. } \\
\text { Assistência terapêutica } \\
\text { multiprofissional. }\end{array}$ & $\begin{array}{c}\text { Universalidade; } \\
\text { Equidade; } \\
\text { Regionalização; } \\
\text { Hierarquização; } \\
\text { Intersetorialidade; } \\
\text { Participação popular; } \\
\text { Integralidade; } \\
\text { Cuidado multiprofissional; } \\
\text { Apoio ao autocuidado. }\end{array}$ \\
\hline $\begin{array}{l}\text { Portaria no } 425 \text {, de } 19 \\
\text { de março de } 201313 . \\
\text { Estabelece } \\
\text { regulamento técnico, } \\
\text { normas e critérios para } \\
\text { o serviço de assistência } \\
\text { de alta complexidade } \\
\text { ao indivíduo com } \\
\text { obesidade. }\end{array}$ & $\begin{array}{l}\text { Os estabelecimentos de saúde habilitados } \\
\text { como assistência de alta complexidade } \\
\text { ao indivíduo com obesidade devem estar } \\
\text { inseridos na organização da linha de cuidado } \\
\text { do sobrepeso e obesidade na Rede de Atenção } \\
\text { às Pessoas com Doenças Crônicas; } \\
\text { As Secretarias de Saúde dos Estados, ao } \\
\text { indicarem o estabelecimento que prestará a } \\
\text { assistência de alta complexidade ao indivíduo } \\
\text { com obesidade, devem estabelecer em } \\
\text { conjunto com seus respectivos municípios, } \\
\text { os fluxos e mecanismos de referência e } \\
\text { contrarreferência dos indivíduos obesos grau } \\
\text { III e grau II com comorbidades, de acordo } \\
\text { com o estabelecido na linha de cuidado da } \\
\text { obesidade na RAS das pessoas com doenças } \\
\text { crônicas. }\end{array}$ & $\begin{array}{l}\text { Assistência terapêutica } \\
\text { multiprofissional. Avaliação clínica } \\
\text { realizada por equipe multiprofissional. } \\
\text { Acompanhamento dos indivíduos com } \\
\text { obesidade, conforme estabelecido } \\
\text { na linha de cuidado do sobrepeso } \\
\text { e obesidade na Rede de Atenção às } \\
\text { Pessoas com Doenças Crônicas. }\end{array}$ & $\begin{array}{l}\text { Universalidade; } \\
\text { Equidade; } \\
\text { Regionalização; } \\
\text { Hierarquização; } \\
\text { Integralidade. }\end{array}$ \\
\hline
\end{tabular}

(continua) 
Quadro 2 (continuação)

\begin{tabular}{|c|c|c|c|}
\hline \multirow{2}{*}{$\begin{array}{l}\text { FONTES } \\
\text { Documentos } \\
\text { analisados }\end{array}$} & \multicolumn{3}{|c|}{ DIMENSÕES DE ANÁLISE } \\
\hline & Organização institucional & Práticas de atenção à saúde & Princípios e diretrizes \\
\hline $\begin{array}{l}\text { Portaria no } 483 \text {, de } 1 \text { o } \\
\text { de abril de } 201411 \text {. } \\
\text { Redefine a RAS das } \\
\text { pessoas com doenças } \\
\text { crônicas no âmbito } \\
\text { do SUS e estabelece } \\
\text { diretrizes para a } \\
\text { organização de suas } \\
\text { linhas de cuidado. }\end{array}$ & 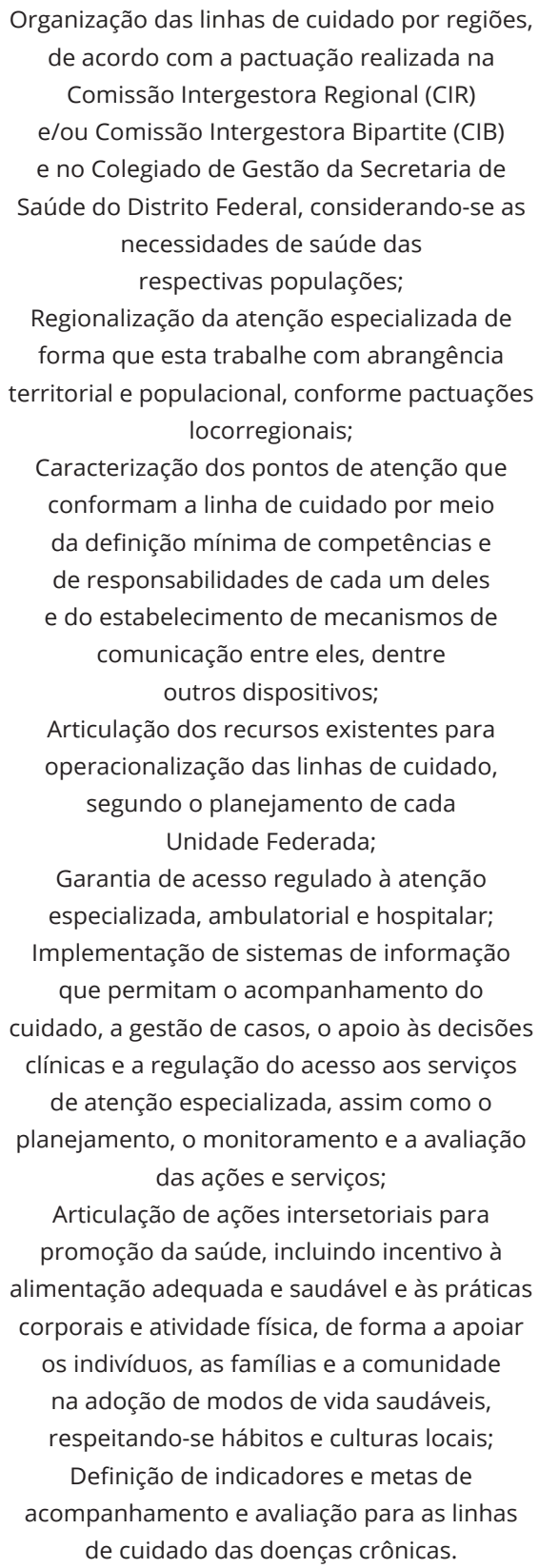 & $\begin{array}{l}\text { Apoio diagnóstico e terapêutico } \\
\text { adequado para prevenção e tratamento } \\
\text { das doenças crônicas, com efetivação } \\
\text { de um modelo centrado no usuário, } \\
\text { baseado nas suas necessidades de } \\
\text { saúde, respeitando-se as diversidades } \\
\text { étnico-raciais, culturais, sociais e } \\
\text { religiosas. } \\
\text { Avaliação e acompanhamento } \\
\text { periódicos das pessoas que } \\
\text { apresentam doenças crônicas de forma } \\
\text { integral e criteriosa, considerando-se } \\
\text { a totalidade dos fatores de risco a que } \\
\text { estão sujeitas e não apenas o potencial } \\
\text { isolado de cada diagnóstico clínico ou } \\
\quad \text { laboratorial. } \\
\text { Estabelecimento de estratégias para } \\
\text { apoio ao autocuidado de maneira } \\
\text { a garantir a autonomia do usuário, } \\
\text { o conhecimento sobre sua saúde e } \\
\text { a corresponsabilização dos atores } \\
\text { envolvidos. } \\
\text { multiprofissional - Trabalho }\end{array}$ & $\begin{array}{c}\text { Integralidade; } \\
\text { Humanização; } \\
\text { Cuidado multiprofissional; } \\
\text { Corresponsabilização do } \\
\text { profissional e do usuário } \\
\text { com especial atenção para } \\
\text { a construção do vínculo, da } \\
\text { autonomia do usuário e do } \\
\text { autocuidado; } \\
\text { Intersetorialidade. }\end{array}$ \\
\hline $\begin{array}{l}\text { Cadernos de Atenção } \\
\text { Básica } 3518 . \\
\text { Estratégias para o } \\
\text { cuidado da pessoa com } \\
\text { doença crônica. }\end{array}$ & $\begin{array}{l}\text { O cuidado da pessoa com doença crônica } \\
\text { deve considerar: programação da assistência } \\
\text { conforme a necessidade da população; planos } \\
\text { de recepção ou acolhimento; diretrizes clínicas } \\
\text { baseadas em evidências; planejamento } \\
\text { estratificado segundo os riscos individualizado. }\end{array}$ & $\begin{array}{c}\text { Potencializar a "gestão do caso" } \\
\text { (integrar, coordenar e advogar pelos } \\
\text { indivíduos, famílias ou grupos que } \\
\text { necessitam de cuidados de } \\
\text { longo prazo). } \\
\text { Discute abordagens para mudança } \\
\text { de comportamento e apresenta } \\
\text { diferentes metodologias utilizadas na } \\
\text { educação para o autocuidado. }\end{array}$ & $\begin{array}{c}\text { Integralidade do cuidado } \\
\text { em saúde; } \\
\text { Autocuidado. }\end{array}$ \\
\hline
\end{tabular}

(continua) 
Quadro 2 (continuação)

\begin{tabular}{|c|c|c|c|}
\hline FONTES & \multicolumn{3}{|c|}{ DIMENSÕES DE ANÁLISE } \\
\hline $\begin{array}{l}\text { Documentos } \\
\text { analisados }\end{array}$ & Organização institucional & Práticas de atenção à saúde & Princípios e diretrizes \\
\hline $\begin{array}{l}\text { Cadernos de Atenção } \\
\text { Básica } 3817 . \\
\text { Estratégias para o } \\
\text { cuidado da pessoa } \\
\text { com doença crônica e } \\
\text { obesidade. }\end{array}$ & $\begin{array}{l}\text { Organização da atenção para prevenção e } \\
\text { controle da obesidade na perspectiva da RAS } \\
\text { considerando: } \\
\text { Identificação dos pontos de atenção e suas } \\
\text { respectivas competências (que ações estes } \\
\text { pontos de atenção devem desenvolver } \\
\text { - promocionais, preventivas, curativas, } \\
\text { cuidadoras, reabilitadoras e paliativas); } \\
\text { Identificação do sistema logístico para } \\
\text { o cuidado com o usuário (Cartão SUS - } \\
\text { Prontuário Eletrônico - centrais de regulação e } \\
\text { sistema de transporte sanitário); } \\
\text { Identificar as necessidades das UBS quanto ao } \\
\text { sistema de apoio; } \\
\text { Desenho do itinerário terapêutico e relacionar } \\
\text { as necessidades logísticas e de apoio } \\
\text { necessárias; } \\
\text { Identificação do sistema de gestão da rede - } \\
\text { Comissão Intergestora Regional; } \\
\text { Definição de metas e indicadores que serão } \\
\text { utilizados para monitoramento e avaliação. }\end{array}$ & $\begin{array}{l}\text { Identificar a população com sobrepeso } \\
\text { e obesidade e os diferentes estratos } \\
\text { de risco e realizar a programação de } \\
\text { cuidado definidos localmente. } \\
\text { Apresenta o modelo transteórico, } \\
\text { cujo componente central corresponde } \\
\text { aos estágios de mudança de } \\
\text { comportamento e a abordagem da } \\
\text { Terapia Cognitiva Comportamental. } \\
\text { Projeto Terapêutico Singular. } \\
\text { Abordagem familiar da obesidade. } \\
\text { Resgate da culinária como parte das } \\
\text { práticas de atenção à saúde. }\end{array}$ & $\begin{array}{c}\text { Intersetorialidade; } \\
\text { Equidade; } \\
\text { Desenvolvimento humano } \\
\text { e social; } \\
\text { Diversidade; } \\
\text { Qualidade de vida; } \\
\text { Empoderamento para } \\
\text { autocuidado; } \\
\text { Integralidade e } \\
\text { Iongitudinalidade do } \\
\text { cuidado; } \\
\text { Acolhimento; } \\
\text { Cuidado multiprofissional. }\end{array}$ \\
\hline
\end{tabular}

(continua) 
Quadro 2 (continuação)

\begin{tabular}{|c|c|c|c|}
\hline FONTES & \multicolumn{3}{|c|}{ DIMENSÕES DE ANÁLISE } \\
\hline $\begin{array}{l}\text { Documentos } \\
\text { analisados }\end{array}$ & Organização institucional & Práticas de atenção à saúde & Princípios e diretrizes \\
\hline $\begin{array}{l}\text { Organização regional } \\
\text { da linha de cuidado do } \\
\text { sobrepeso e obesidade } \\
\text { na RAS das pessoas } \\
\text { com doenças crônicas } \\
\text { (Manual Instrutivo) } 34 . \\
\text { Apresenta instruções } \\
\text { para apoiar os gestores } \\
\text { na organização da } \\
\text { linha de cuidado } \\
\text { do sobrepeso e da } \\
\text { obesidade na RAS às } \\
\text { pessoas com doenças } \\
\text { crônicas no estado, no } \\
\text { município e nas regiões } \\
\text { de saúde. }\end{array}$ & 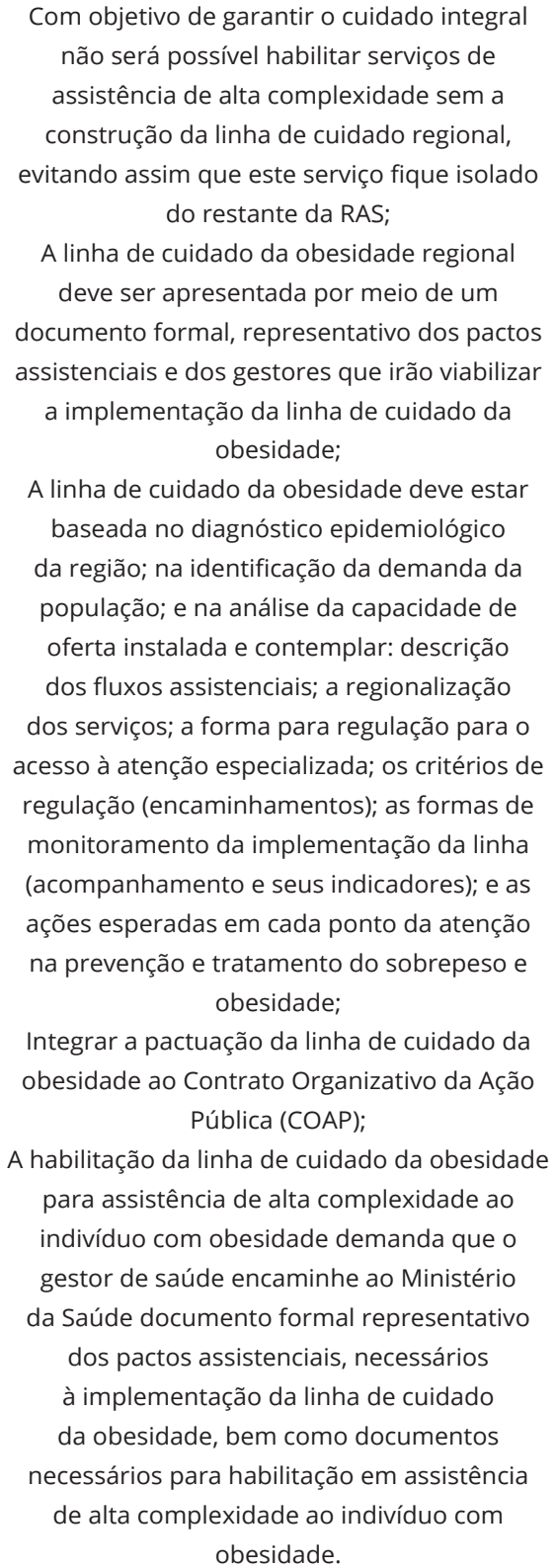 & $\begin{array}{l}\text { Para a prevenção e controle da } \\
\text { obesidade, as atividades devem ser } \\
\text { planejadas de forma compartilhada } \\
\text { com a comunidade, permitindo } \\
\text { considerar as características sociais e } \\
\text { culturais do ambiente; } \\
\text { Definir plano de metas individual; } \\
\text { Cuidado clínico longitudinal. }\end{array}$ & $\begin{array}{l}\text { Articulação intra e } \\
\text { intersetorial; } \\
\text { Regionalização dos } \\
\text { serviços; } \\
\text { Autocuidado; } \\
\text { Integralidade; } \\
\text { Longitudinalidade do } \\
\text { Cuidado. }\end{array}$ \\
\hline
\end{tabular}

(continua) 
Quadro 2 (continuação)

\begin{tabular}{|c|c|c|c|}
\hline FONTES & \multicolumn{3}{|c|}{ DIMENSÕES DE ANÁLISE } \\
\hline $\begin{array}{l}\text { Documentos } \\
\text { analisados }\end{array}$ & Organização institucional & Práticas de atenção à saúde & Princípios e diretrizes \\
\hline $\begin{array}{l}\text { Perspectivas e desafios } \\
\text { no cuidado às pessoas } \\
\text { com obesidade no } \\
\text { SUS: resultados } \\
\text { do laboratório de } \\
\text { inovação no manejo da } \\
\text { obesidade nas RAS } 32 . \\
\text { Apresenta diagnóstico } \\
\text { da obesidade no Brasil, } \\
\text { analisa condicionantes, } \\
\text { práticas de atenção } \\
\text { à saúde e diferentes } \\
\text { experiências de manejo } \\
\text { da obesidade. }\end{array}$ & $\begin{array}{l}\text { Com base nas Portarias no } 424 \text { e no } 425 \text { que } \\
\text { definem as diretrizes para a organização da } \\
\text { prevenção e do tratamento do sobrepeso e } \\
\text { obesidade como linha de cuidado prioritária da } \\
\text { RAS das pessoas com doenças crônicas. }\end{array}$ & $\begin{array}{l}\text { O documento dedica um capítulo para } \\
\text { discussão de modelos de atenção à } \\
\text { saúde e destaca o desafio de superação } \\
\text { do modelo biomédico por ser } \\
\text { reducionista e pouco resolutivo. } \\
\text { Cuidado integral em saúde. } \\
\text { Cuidado interdisciplinar - Trabalho } \\
\text { em saúde realizado por equipes } \\
\text { multiprofissionais. } \\
\text { Longitudinalidade do cuidado } \\
\text { Projeto Terapêutico Singular } \\
\text { Projeto de Saúde no Território } \\
\text { Abordagem familiar da obesidade. }\end{array}$ & $\begin{array}{c}\text { Universalidade; } \\
\text { Equidade; } \\
\text { Regionalização; } \\
\text { Intersetorialidade; } \\
\text { Participação; } \\
\text { Integralidade no cuidado; } \\
\text { Humanização; } \\
\text { Autonomia e } \\
\text { Empoderamento dos } \\
\text { indivíduos; } \\
\text { Acolhimento; } \\
\text { Vínculo; } \\
\text { Corresponsabilização. }\end{array}$ \\
\hline
\end{tabular}

(continua) 
Quadro 2 (continuação)

\begin{tabular}{|c|c|c|c|}
\hline \multirow{2}{*}{$\begin{array}{l}\text { FONTES } \\
\text { Relatos }\end{array}$} & \multicolumn{3}{|c|}{ DIMENSÕES DE ANÁLISE } \\
\hline & Organização institucional & Práticas de atenção à saúde & Princípios e diretrizes \\
\hline $\begin{array}{l}\text { Entrevistas e grupos } \\
\text { focais com apoiadores } \\
\text { regionais da atenção } \\
\text { básica e coordenadores } \\
\text { regionais e municipais } \\
\text { da ATAN. }\end{array}$ & 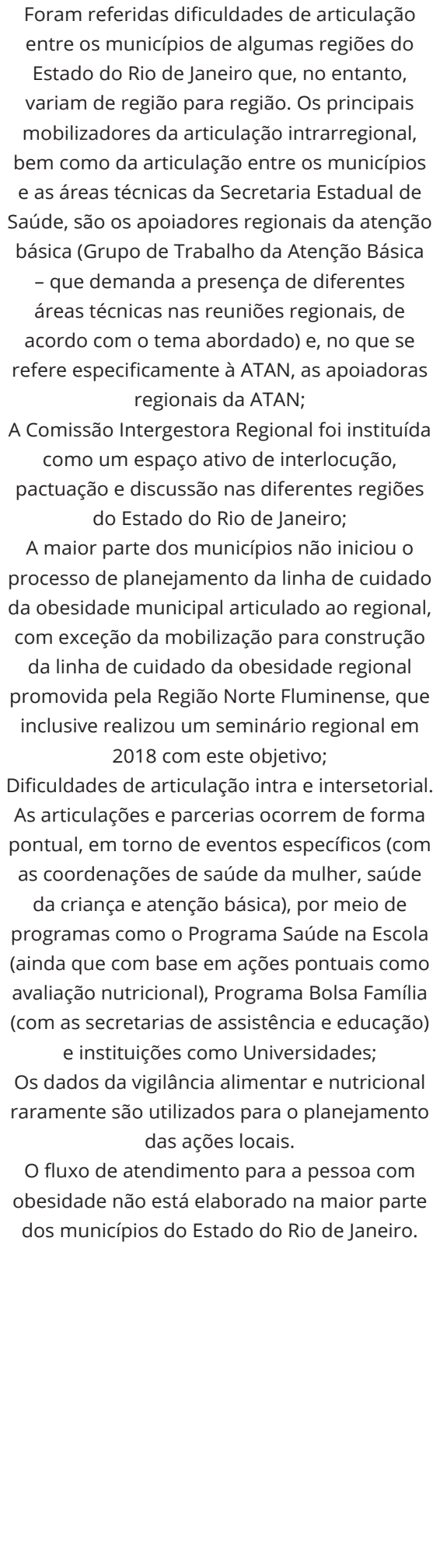 & 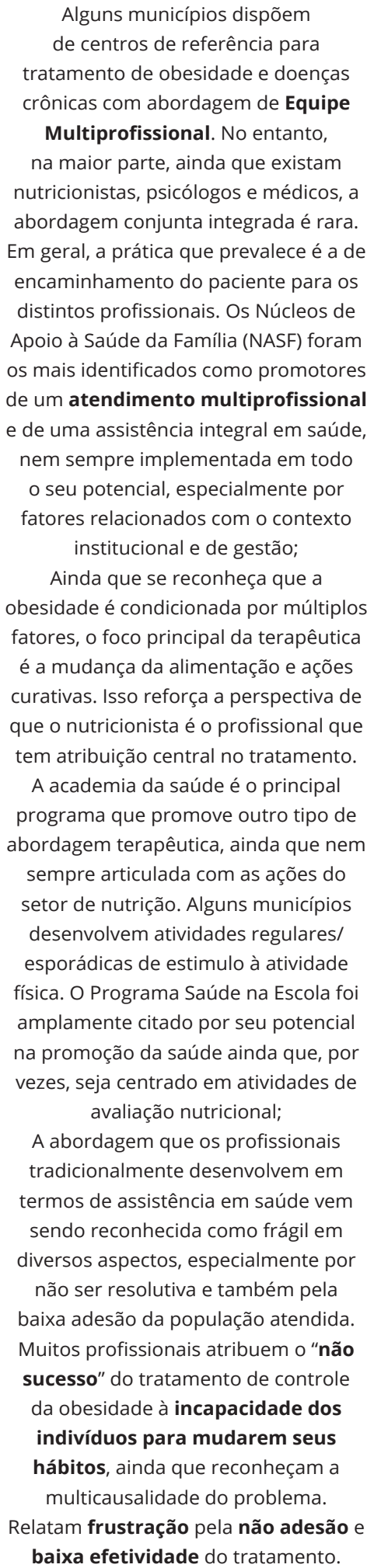 & $\begin{array}{l}\text { Os depoentes destacam } \\
\text { principalmente a } \\
\text { importância da articulação } \\
\text { intra e intersetorial no } \\
\text { âmbito da gestão e do } \\
\text { atendimento por equipe } \\
\text { multiprofissional no } \\
\text { âmbito da atenção à saúde, } \\
\text { ainda que reconheçam } \\
\text { os desafios para } \\
\text { implementação destes } \\
\text { princípios. }\end{array}$ \\
\hline
\end{tabular}

ATAN: Área Técnica de Alimentação e Nutrição; DCNT: doenças crônicas não transmissíveis; IMC: índice de massa corporal; RAS: Rede de Atenção à Saúde; SISVAN: Sistema de Vigilância Alimentar e Nutricional; SUS: Sistema Único de Saúde; UBS: unidades básicas de saúde. 
O mapeamento das ações de prevenção e controle da obesidade no Estado do Rio de Janeiro, os relatos dos profissionais sobre os desafios enfrentados, bem como a análise da trajetória institucional de cuidado dos usuários entrevistados, indicaram que a assistência em saúde decorre de um diagnóstico nutricional que não é precoce e que, ao contrário, sinaliza um quadro já instalado e, por vezes, avançado do problema. As consultas individuais e atividades em grupo (grupos educativos, de apoio, salas de espera) foram as principais ações destacadas pelos depoentes, além de outras atividades de promoção da saúde e prevenção de doenças crônicas, tais como: grupos de caminhada; Programa Academia da Saúde; Programa Saúde na Escola (PSE); ações de promoção da alimentação saudável direcionadas para usuários do Programa Bolsa Família ou em parceria com o Núcleo de Apoio à Saúde da Família (NASF). Destacaram também os princípios da articulação intra e intersetorial e a atuação multiprofissional como relevantes para as práticas de atenção integral. A análise documental indicou como as principais categorias que expressam a articulação entre as práticas e os princípios que balizam os modelos assistenciais propostos nas políticas: (1) as práticas de abordagem integral ao usuário, baseadas nos princípios da integralidade e autocuidado; (2) as práticas de trabalho em equipe multiprofissional, baseadas no princípio da interdisciplinaridade articulado ao princípio da intersetorialidade circunscrita ao contexto territorial comunitário; (3) as práticas de acolhimento e construção de vínculo entre profissional e usuário, baseadas no princípio da humanização do atendimento (Quadro 2).

\section{Abordagem integral do usuário}

Os Cadernos de Atenção Básica 16,17 propõem práticas de saúde baseadas em princípios que pautam a ESF, que têm na integralidade do cuidado um de seus eixos identitários e são caracterizadas como aquelas que: correlacionam questões sociais, psicológicas, genéticas, clínicas, simbólicas e alimentares implicadas no sobrepeso/obesidade, tanto em indivíduos quanto em coletividades 16; valorizam outros ganhos para além da perda de peso, tais como o bem-estar, autoestima e humor do indivíduo, a melhoria nos resultados dos exames laboratoriais, no sono, na função intestinal, na pressão arterial, na qualidade de vida 16. Os Cadernos de Atenção Básica 3817 abordam de forma mais aprofundada: (1) a organização da atenção para a prevenção e controle da obesidade na perspectiva das RAS e os critérios para a estratificação do risco para a modelagem da linha de cuidado da obesidade com base, principalmente, na avalição nutricional e no diagnóstico de comorbidades, considerando inclusive que as Portarias que instituíram a linha de cuidado da obesidade já haviam sido publicadas; (2) os transtornos alimentares 17; (3) o tratamento cirúrgico, indicando elementos que subsidiam a atenção dietética nos períodos pré e pós-operatórios 17.

Segundo os Cadernos de Atenção Básica 12 16, a abordagem integral do usuário demanda considerar o contexto familiar e social; atuar de forma integrada à vigilância em saúde; identificar situações de risco associadas ao sobrepeso/obesidade, tais como baixa autoestima, questões de gênero, violência, desemprego, uso do álcool, do tabaco e outras drogas. Considera-se que a "construção de um processo terapêutico contextualizado à realidade da população pode gerar dilemas para os profissionais quanto às frustrações decorrentes dos limites que a atenção individualizada enfrenta para atuar nos fatores relacionados ao ambiente obesogênico e que demandam outras políticas públicas" 16 (p. 83). Além disso, estabelecer adesão e continuidade ao tratamento e consolidar a integralidade entre os pontos de atenção do sistema são desafios a serem enfrentados, que demandam uma atuação profissional que possibilite uma terapêutica adequada às singularidades de cada caso.

Esses desafios foram referidos nos depoimentos dos profissionais de saúde do Estado do Rio de Janeiro que sinalizaram sua "frustração", muitas vezes acompanhada de um sentimento de impotência e despreparo para lidar com a complexidade das doenças crônicas/obesidade, incluindo os contextos "pré" e "pós" cirurgia bariátrica. Os relatos de todos os segmentos de depoentes destacam as dificuldades de aceitação/adesão dos pacientes aos processos terapêuticos e de retorno às consultas. Em geral, os usuários procuram o SUS por complicações relacionadas à obesidade, tais como diabetes e hipertensão, mais do que pela obesidade em si. Além disso, há pouca integração das ações de promoção da saúde no cotidiano de cuidado, o que remete à importância de um planejamento integrado de ações pelos múltiplos setores envolvidos. 
Diversos profissionais (nutricionistas, enfermeiros, médicos) reconhecem que a obesidade é condicionada por múltiplos fatores (genéticos, ambientais, culturais, influência da publicidade e da oferta de produtos ultraprocessados nos diferentes espaços de vivência, inclusive nas escolas). Os fatores emocionais, ou psicológicos, além do contexto familiar, foram amplamente destacados como condicionantes importantes do problema que trazem desafios específicos para o atendimento individual e em grupo. Consideram que a obesidade é um problema complexo que demanda a ação de diferentes setores, equipe multiprofissional e transformação de fatores ambientais. No entanto, paradoxalmente, sinalizam que a baixa adesão ao tratamento é fruto de uma dificuldade do indivíduo obeso em mudar seus hábitos alimentares. Essa perspectiva culpabilizadora pode ser exemplificada em trechos dos depoimentos: "O paciente não quer ser tratado, não quer ouvir"; "Nós atendemos, damos medicamento, fazemos consulta, mas o paciente quer?”; "A criança não quer fazer exercício físico, algumas mães não querem mudanças, é uma questão de cultura" (Grupos focais).

"Eles (os profissionais) entendem que a obesidade é, literalmente, uma sem-vergonhice do paciente. Essa é a palavra, é a frase, infelizmente, é o que mais a gente escuta dos profissionais. E é na porta de entrada, tanto médico quanto agente comunitário de saúde". A primeira pergunta que a gente faz é: "o que você entende como obesidade?" "Pouca vergonha". "Todos falam a mesma coisa. Só que o enfermeiro fala de uma forma, o médico de outra, mas o significado é o mesmo" (Entrevista com Coordenação Municipal de ATAN).

A adesão aos processos terapêuticos é especialmente desafiadora, considerando que nem todos os tratamentos são adequados às necessidades dos indivíduos com doenças crônicas, que demandam apoio continuado e ações que vão além dos limites biomédicos. Os Cadernos de Atenção Básica obesidade 16,17 reconhecem essa complexidade, sinalizam a frustração dos profissionais em relação aos limites do tratamento individualizado 16 e apresentam algumas metodologias e ferramentas que podem potencializar a adesão, como o chamado modelo transteorético de avaliação dos estágios de mudança comportamental 17 , que indica como diagnosticar tais estágios visando a uma terapêutica individualmente adequada. A Teoria Cognitiva Comportamental (TCC), que é uma abordagem da psicologia baseada na transformação de pensamentos disfuncionais, é sugerida nos Cadernos de Atenção Básica 3817 para o tratamento da obesidade e explicada de forma mais aprofundada nos Cadernos de Atenção Básica 35 de doenças crônicas 18 que discute diferentes metodologias de educação para o autocuidado.

Os Cadernos de Atenção Básica obesidade 16,17 abordam como objetivos norteadores das práticas de atenção integral à saúde a promoção do autocuidado e do empoderamento do usuário (reforçados nos Cadernos de Atenção Básica 38 17). No entanto, também são os Cadernos de Atenção Básica doenças crônicas 18 que aprofundam a discussão sobre o conceito de autocuidado considerado, para além da responsabilidade do indivíduo e de sua família, em uma relação de diálogo entre os "saberes de cuidar de si" e os "saberes de cuidar do outro". Nas doenças crônicas, o autocuidado é uma tarefa por toda a vida e vai muito além das mudanças comportamentais, sendo entendido como uma construção conjunta dos processos de cuidado centrados na pessoa e no diálogo.

Os Cadernos de Atenção Básica obesidade 16,17 tratam dessas questões de forma superficial e devem ser lidos juntamente com os Cadernos de Atenção Básica doenças crônicas 18. Ainda assim, destacam ferramentas e métodos terapêuticos, princípios como o acolhimento e vínculo, valorizam a fala e a escuta da história psicossocial, a proximidade com a realidade da comunidade, o apoio emocional, o estímulo ao autocuidado, a problematização e o "saber pensar", e ressaltam como as atividades em grupo e individuais podem potencializar-se mutuamente 16.

\section{Trabalho em equipe multiprofissional, interdisciplinaridade e intersetorialidade}

Segundo os Cadernos de Atenção Básica 16, a combinação entre o olhar generalista, o trabalho multiprofissional e a articulação intersetorial pode potencializar a resolutividade dos modelos assistenciais. Essa perspectiva demanda do profissional algumas habilidades e competências técnicas, além de sensibilidade, reflexão crítica, criatividade, visão interdisciplinar, cooperatividade, problematização e o "saber pensar" criticamente de modo a potencializar o usuário como sujeito autônomo da ação.

É interessante notar que a abordagem desses temas nos Cadernos de Atenção Básica 16 é integrada, ou seja, não dissocia a interdisciplinaridade, a construção de habilidades profissionais e a intersetorialidade, pois considera que a busca da interdisciplinaridade associada com a intersetorialidade (articulação dos profissionais com redes mais complexas que contemplem outros saberes) poten- 
cializa a construção de habilidades e competências profissionais. A intersetorialidade é considerada baseando-se no desenvolvimento de ações no território (parcerias na comunidade com equipamentos sociais que não necessariamente se situam no "setor" saúde) e também com base em uma concepção mais ampla da promoção da saude, que prevê a articulação de ações de diferentes setores governamentais para garantia da saúde 16,17. Trata-se de uma abordagem da intersetorialidade distinta daquela apresentada na Estratégia Intersetorial de Prevenção e Controle da Obesidade (EIPCO), que considera a articulação de setores no âmbito do sistema alimentar, como analisado por Dias et al 2. O propósito dos Cadernos de Atenção Básica é subsidiar a atuação dos profissionais de saúde da atenção básica, portanto, a abordagem da intersetorialidade circunscrita à promoção da saúde e ao território é adequada e coerente com a perspectiva da própria ESF e do planejamento territorial integrado em saúde. Cabe considerar que a intersetorialidade na perspectiva da promoção da saúde, conforme apontado nos Cadernos de Atenção Básica 16, é a que mais se aproxima e dialoga com a EIPCO.

Os depoimentos dos profissionais destacam principalmente as parcerias intrasetoriais relacionadas com o Programa Academia da Saúde, Programa Saúde na Escola, programa Bolsa Família e o NASF. O apoio matricial interdisciplinar é considerado um grande potencializador da resolutividade das equipes da atenção básica, ao promover a ampliação dos saberes acerca da complexidade desses agravos e permitir uma melhor oferta de cuidados 17 . Os NASF cumprem esse papel e foram amplamente destacados pelos profissionais como estratégia que potencializa a atenção integral à saúde, ainda que por vezes suas ações sejam circunscritas ao atendimento individualizado.

Considerando os desafios para a consolidação de um processo terapêutico interdisciplinar, os Cadernos de Atenção Básica 16 destacam dilemas para a atuação em equipe multiprofissional, como a definição de competências e dos limites de ação de cada profissão. A importância dos psicólogos foi amplamente reiterada pelos profissionais do Estado do Rio de Janeiro que reconhecem as dificuldades em lidar com os condicionantes "emocionais" da obesidade.

\section{Acolhimento, construção de vínculo e humanização}

Os Cadernos de Atenção Básica 16,17 reiteram que a construção de vínculo e o estabelecimento de uma relação de confiança entre profissional e usuário potencializam a adesão ao tratamento, além de qualificar o trabalho em saúde e constituir um recurso terapêutico fundamental. O vínculo se refere não apenas à relação entre profissional e usuário, mas também à organização da RAS, uma vez que as equipes de atenção básica devem manter o vínculo com os indivíduos enquanto são assistidos nos serviços de atenção especializada e também com os profissionais destes serviços, para que seja coordenadora do cuidado 17.

É interessante notar que os documentos indicam que esse processo de construção se desenvolve no cotidiano dos serviços por meio das rotinas, dos instrumentos de trabalho, das relações pessoais, da integração dos profissionais, da sensibilização e capacidade de escuta, do incentivo à fala do usuário, da valorização de suas vivências, do olhar atento para suas queixas, dúvidas, medos e ansiedades 16. A opção por métodos e instrumentos que possibilitem compartilhar experiências contribui para maior autonomia, autoestima e crescimento compartilhado 16 . $\mathrm{O}$ acolhimento, portanto, é abordado nos documentos como uma estratégia fundamental para a qualificação da atenção básica, inclusive porque visa a promover mudanças no processo de trabalho, na reestruturação dos serviços de saúde no sentido da integralidade, humanização, equidade e resolutividade da atenção 16.

\section{Discussão}

Os princípios e diretrizes que pautam as propostas governamentais de atenção à pessoa com doenças crônicas e obesidade aqui analisados reiteram a necessidade de superação do modelo biomédico caracterizado por baixa adesão e resolutividade 19,20. Por outro lado, sinalizam que a integralidade é potencializada pela terapêutica multiprofissional compartilhada com o usuário e pautada no contexto socioterritorial, como preconizado pela ESF 5,21,22. Portanto, as estratégias para reorientar os modelos assistenciais vigentes devem considerar os relatos dos profissionais sobre sua "frustração" advinda da baixa adesão da população aos processos terapêuticos, impotência e despreparo para 
lidar com a complexidade das doenças crônicas e obesidade, além das dificuldades para a atuação em equipe multidisciplinar.

Tais desafios vêm sendo registrados por outros estudos, tanto no contexto nacional quanto internacional. Uma avaliação da atenção nutricional aos adultos com sobrepeso no Município de Santos, São Paulo 23, concluiu que o excesso de peso não é um desfecho pautado na atenção básica nem na atenção secundária, e que o modelo assistencial predominante é prescritivo e pouco potente para promover a autonomia dos sujeitos. Cabe problematizar se as habilidades e competências que potencializam a atenção integral à saúde vêm sendo construídas nos distintos processos de formação dos profissionais, incluindo a consolidação do trabalho em equipe multiprofissional que, como indicado nos documentos, é em si pedagógico. Foram destacados como principais desafios para a assistência terapêutica multiprofissional: a clareza quanto aos limites e definição dos papéis de cada profissional; dificuldades operacionais, institucionais e de gestão. Vale também considerar como se dá a apropriação crítica de alguns instrumentais da psicologia que são abordados nos Cadernos de Atenção Básica 16,17,18, como a TCC, especialmente por profissionais não psicólogos e/ou que têm dificuldade em atuar em equipe integrada por um psicólogo. O reconhecimento da importância desse profissional para a construção de um processo terapêutico adequado foi reiterado pelos depoentes. Além disso, a equipe multiprofissional, incluindo o psicólogo, pode ser fundamental não só para a compreensão da multicausalidade do processo saúde/doença do indivíduo com obesidade, mas também para subsidiar os profissionais de saúde na compreensão dos desafios para a adesão. Isso envolve, por um lado, a problematização sobre a relação que se estabelece entre profissional e usuário, a corresponsabilização, a autonomia e o autocuidado e, por outro, o manejo de emoções que afetam os próprios profissionais de saúde no curso de um processo terapêutico desafiador. Nesse sentido, a forma articulada como os documentos analisados tratam princípios e diretrizes referentes à organização institucional e às práticas de atenção, especialmente por não dissociarem a interdisciplinaridade, a intersetorialidade e a construção de habilidades e competências profissionais, é bastante interessante pois baseia-se no pressuposto de que a formação das habilidades necessárias para a atenção integral à saúde é potencializada pela atuação em equipes multiprofissionais.

Borges \& Porto 19 indicam que a adesão dos pacientes ao tratamento é desafiadora e que os profissionais revelam um sentimento de impotência diante de questionamentos recorrentes sobre os motivos para tal. Os autores apontam a importância das estratégias de educação e saúde na perspectiva de reorientação do modelo assistencial, mas consideram que um dos desafios é superar os próprios paradigmas clássicos de educação em saúde que ainda reforçam ações reducionistas, verticais, que não são baseadas em valores/princípios como equidade e participação social. Além disso, ressaltam o fato de que a maioria das pesquisas sobre "adesão" e "não adesão" não contempla a subjetividade dos usuários, suas necessidades e dificuldades e enfatiza exclusivamente a precisão com que seguem as recomendações dos profissionais de saúde. Para os autores, o conceito de adesão implica a postura ativa frente ao autocuidado e deve ser questionado para que a responsabilização sobre o problema não recaia sobre o indivíduo, como alertam os documentos aqui analisados. No entanto, a percepção dos profissionais entrevistados, diante das frustrações que vivenciam com a baixa resolutividade, aliadas aos múltiplos problemas que enfrentam em seu cotidiano de trabalho, pode reforçar a perspectiva de responsabilização do usuário e não da corresponsabilização entre profissional e usuário, por meio da construção de vínculo e de autonomia (princípios sinalizados nos documentos governamentais). Portanto, lidar com essa questão é um importante desafio na reorientação do modelo assistencial.

Para analisar melhor esse processo, vale problematizar não só como os profissionais compreendem a obesidade (se consideram ou não os múltiplos condicionantes), mas também especial atenção deve ser dada para as concepções que têm sobre o indivíduo obeso.

Francisco \& Diez-Garcia 20 reiteram que a abordagem terapêutica da obesidade tem se detido no modelo biológico do qual derivam estratégias que são insuficientes para dar conta da complexidade do problema. Analisam vários estudos que indicam como as atitudes negativas dos próprios profissionais de saúde em relação ao excesso de peso podem afetar o tratamento e o julgamento clínico, dificultar o acesso aos serviços de saúde e condicionar, inclusive, o tempo de consulta. Estudos abordados pelos autores sinalizam que a maioria dos profissionais entrevistados não se sente qualificado para tratar a obesidade, o que os leva a sentimentos de limitação e frustração. Mesmo entre grupos especializados 
e interessados em tratar a obesidade existem níveis consideráveis de preconceito - próximos ao da população em geral.

Assis 24 também ressalta as frustrações e outras reações, até mesmo a raiva, expressas por profissionais que lidam com o tratamento da obesidade e com as "resistências" dos usuários em mudar seus hábitos, o que por vezes é atribuído a uma postura de "relaxamento da família" e "falta de disciplina". Portanto, apesar das evidências científicas de que os fatores psicossociais, genéticos, metabólicos e hormonais condicionam a obesidade, ainda sobressai a hipervalorização das causas "pessoais" 20 e os profissionais de saúde acabam seguindo esta perspectiva, como observado no presente estudo. "Pacientes obesos" são rotulados como aqueles que não se cuidam ou que não querem se cuidar, que gastam dinheiro público com seu tratamento e são punidos por este dilema moral de culpa individual. A responsabilidade pessoal se torna peça central no processo de estigmatização da pessoa com obesidade, o que só reitera a importância de se problematizar o conceito de autocuidado para que não reforce esta perspectiva culpabilizadora 20 .

No âmbito internacional, desafios semelhantes vêm sendo registrados por estudos que analisaram atitudes de profissionais de saúde em relação à obesidade e implicações nas práticas de atenção. Estudo de revisão sistemática 25 e pesquisas realizadas em Portugal 26 e nos Estados Unidos 27, indicaram: a dificuldade dos profissionais em lidar com a obesidade, devida, em parte, à abordagem biomédica 25,27; o ceticismo em relação ao tratamento; concepções ambivalentes sobre a eficácia das intervenções; a culpabilização e a visão negativa e estigmatizada do indivíduo com obesidade 25,26; sentimentos de impotência e frustração por parte dos profissionais com o insucesso do tratamento. Uma perspectiva comum aos discursos de médicos, enfermeiros e nutricionistas refere-se aos principais desafios enfrentados no processo terapêutico: a desmotivação dos obesos, a falta de tempo na consulta e a ausência de recursos, como a falta de nutricionistas nas instituições 26 . Ainda assim, uma revisão integrativa indicou que as atitudes negativas dos profissionais em relação à obesidade tendem a melhorar com o tempo 28. Estudos realizados em Portugal 25,26,29 sinalizaram que, apesar dos nutricionistas 26,29 e enfermeiros 26 , semelhantemente aos médicos, atribuírem o "fracasso" do tratamento aos pacientes obesos, eles acreditam em sua competência profissional e na efetividade da terapêutica e, consequentemente, assumem um papel mais ativo e positivo no processo 26,29 quando comparados aos médicos 26 . No entanto, diferenças no salário, no ambiente de trabalho e nos recursos disponíveis, ou seja, questões relacionadas com a organização institucional afetaram suas práticas 29.

Swinburn et al. 30 reiteram como desafios para a prevenção e o controle da obesidade a culpabilização e a estigmatização do indivíduo, pois deslocam a atenção do sistema obesogênico que produz o problema. Cabe então superar a dicotomia entre a condicionalidade individual e a ambiental da obesidade pois, ainda que a responsabilidade individual seja um fator relevante, o ambiente obesogênico (considerado de forma ampla e diversa) afeta de forma significativa a possibilidade dos indivíduos agirem inclusive a favor dos seus próprios interesses 6 . Nesse sentido, para além das "macro políticas” - regulatórias, fiscais e de promoção da alimentação saudável - evidencia-se, especialmente no controle da obesidade infantil, a eficácia da "abordagem familiar da obesidade" 31, sinalizada nos documentos analisados 16,17,32.

\section{Conclusão}

São múltiplas as fragilidades do modelo assistencial biomédico para lidar com o caráter crônico e multifatorial da obesidade, e as propostas governamentais analisadas pautam-se em princípios e diretrizes de organização institucional e práticas de atenção que visam a reorientar este modelo na direção da integralidade. Os principais desafios das práticas, referidos pelos profissionais e reiterados nos documentos de políticas, relacionam-se com: a resolutividade e a dificuldade de adesão aos processos terapêuticos, que contribuiu para sentimentos de frustração e impotência por parte dos profissionais; a atuação em equipe multiprofissional; o sentimento de despreparo para lidar com a complexidade do problema. Mesmo reconhecendo a multicausalidade da obesidade e a essencialidade de políticas públicas voltadas para afetar os ambientes obesogênicos, há dificuldades em reconhecer os limites do próprio modelo assistencial biomédico, sem cair no foco da culpabilização do indivíduo. Nesse sentido, pode ser fundamental resgatar nos processos de formação e diálogo com os profissionais de 
saúde alguns princípios e diretrizes pautados nos documentos, tais como: o conceito de corresponsabilização entre profissional e usuário, que pode contribuir para evitar os extremos da culpabilização e/ou vitimização; a valorização de outros ganhos para além da perda de peso, que pode ressignificar a concepção de adesão ao tratamento; a atuação multiprofissional para que o conhecimento das diversas áreas contribua para que os profissionais desenvolvam uma compreensão contextualizada e multicausal do processo saúde/ doença, visando à integralidade do cuidado, e para que consigam lidar com seus próprios sentimentos e estigmas em relação à pessoa com obesidade.

\section{Colaboradores}

L. Burlandy, M. R. M. Teixeira, L. M. C. Castro, M. C. C. Cruz, C. R. B. Santos e S. R. Souza participaram da concepção, delineamento, coleta, análise, redação e revisão crítica do manuscrito. L. S. Benchimol, T. S. Araújo, D. B. N. Ramos e T. R. Souza participaram da coleta, análise dos dados e revisão crítica do manuscrito.

\section{Informações adicionais}

ORCID: Luciene Burlandy (0000-0003-08756374); Márcia Regina Mazalotti Teixeira (00000002-3528-5814); Luciana Maria Cerqueira Castro (0000-0003-2793-9950); Myrian Coelho Cunha Cruz (0000-0002-6945-4890); Claudia Roberta Bocca Santos (0000-0002-4312-3049); Simone Raimondi de Souza (0000-0003-1636-7459); Luziene Simões Benchimol (0000-0002-1709-1629); Thays da Silva Araújo (0000-0001-8688-9741); Doralice Batista das Neves Ramos (0000-0003-0572-0915); Thamillys Rodrigues Souza (0000-0002-43284256).

\section{Agradecimentos}

Os autores agradecem o financiamento pela Fundação de Amparo à Pesquisa do Estado do Rio de Janeiro (FAPERJ), por meio de Edital PPSUS $\backslash$ FAPERJ - E - 26\110.293\2014.

\section{Referências}

1. Instituto Brasileiro de Geografia e Estatística. Pesquisa Nacional de Saúde: Brasil e grandes regiões. Rio de Janeiro: Instituto Brasileiro de Geografia e Estatística; 2015.

2. Dias PC, Henriques P, Anjos LA, Burlandy L. Obesidade e políticas públicas: concepções e estratégias adotadas pelo governo brasileiro. Cad Saúde Pública 2017; 33:e00006016.

3. Poston W, Foreyt J, Borrell L, Haddock CK. Challenges in obesity management. Southern Med J 1998; 91:710-20.

4. Swinburn B, Kraak V, Rutter H, Vandevijvere S, Lobstein T, Sacks G, et al. Strengthening of accountability systems to create healthy food environments and reduce global obesity. Lancet $2015 ; 385: 2534-45$.

5. Fertonani HP, Pires DEP, Biff D, Scherer MDA. The health care model: concepts and challenges for primary health care in Brazil. Ciênc Saúde Colet 2015; 20:1869-78.

6. Roberto CA, Swinburn B, Hawkes C, Huang T, Costa SA, Ashe M, et al. Patchy progress on obesity prevention: emerging examples, entrenched barriers, and new thinking. Lancet 2015; 18:2400-9.

7. Teixeira CF. Promoção da saúde e SUS: um diálogo pertinente. In: Teixeira CF, Solla JP, organizadores. Modelo de atenção à saúde: promoção, vigilância e saúde da família. Salvador: EDUFBA; 2006. p. 85-108.

8. Mattos RA. Os sentidos da Integralidade: algumas reflexões acerca de valores que merecem ser definidos. In: Pinheiro R, Mattos RA, organizadores. Os sentidos da integralidade na atenção e no cuidado à saúde. Rio de Janeiro: Abrasco/Universidade do Estado do Rio de Janeiro; 2001. p. 39-84.

9. Silva PFA, Baptista TWF. Os sentidos e disputas na construção da Política Nacional de Promoção da Saúde. Physis (Rio J.) 2014; 24:44165.

10. Ministério da Saúde. Portaria no 4279, de 30 de dezembro de 2010. Estabelece diretrizes para organização da RAS no âmbito do SUS. Diário Oficial da União 2010; $31 \mathrm{dez}$.

11. Ministério da Saúde. Portaria no 483, de 1 de abril de 2014. Redefine a Rede de Atenção à Saúde das Pessoas com Doenças Crônicas no âmbito do Sistema Único de Saúde (SUS) e estabelece diretrizes para a organização das suas linhas de cuidado. Diário Oficial da União 2014; 2 abr. 
12. Ministério da Saúde. Portaria no 424, de 19 de março de 2013. Redefine as diretrizes para a organização da prevenção e do tratamento do sobrepeso e obesidade como linha de cuidado prioritária da Rede de Atenção à Saúde das Pessoas com Doenças Crônicas. Diário Oficial da União 2013; 20 mar.

13. Ministério da Saúde. Portaria no 425, de 19 de março de 2013. Estabelece regulamento técnico, normas e critérios para a Assistência de Alta Complexidade ao Indivíduo com Obesidade. Diário Oficial da União 2013; 20 mar.

14. Ministério da Saúde. Portaria no 62, de 6 de janeiro de 2017. Altera as Portarias no 424/GM/ MS de 19 de março de 2013, que redefine as diretrizes para a organização da prevenção e do tratamento do sobrepeso e obesidade como linha de cuidado prioritária na Rede de Atenção às Pessoas com Doenças Crônicas e no 425/GM/MS de 19 de março de 2013, que estabelece o regulamento técnico, normas e critérios para a Assistência de Alta Complexidade ao Indivíduo com Obesidade. Diário Oficial da União 2017; 9 jan.

15. Ministério da Saúde. Portaria no 252/GM/ MS, de 19 de fevereiro de 2013. Institui a Rede de Atenção à Saúde das Pessoas com Doenças Crônicas no âmbito do Sistema Único de Saúde (SUS). Diário Oficial da União 2013; 20 fev.

16. Departamento de Atenção Básica, Secretaria de Atenção à Saúde, Ministério da Saúde. Obesidade. Brasília: Ministério da Saúde; 2006. (Cadernos de Atenção Básica, 12).

17. Departamento de Atenção Básica, Secretaria de Atenção à Saúde, Ministério da Saúde. Estratégias para o cuidado da pessoa com doença crônica: obesidade. Brasília: Ministério da Saúde; 2014. (Cadernos de Atenção Básica, 38).

18. Departamento de Atenção Básica, Secretaria de Atenção à Saúde, Ministério da Saúde. Estratégias para o cuidado da pessoa com doença crônica. Brasília: Ministério da Saúde; 2014. (Cadernos de Atenção Básica, 35).

19. Borges SAC, Porto PN. Por que os pacientes não aderem ao tratamento? Dispositivos metodológicos para a educação em saúde. Saúde Debate 2014; 38:338-46.

20. Francisco LV, Diez-Garcia RW. Abordagem terapêutica da obesidade: entre conceitos e preconceitos. Demetra 2015; 10:705-16.

21. Navolar TS, Tesser CD, Azevedo E. Contribuições para a construção da nutrição complementar integrada. Interface (Botucatu online) 2012; 16:515-27.

22. Kirk FLS, Penney LT. The role of systems in obesity management and prevention: problems and paradigm shifts. Curr Obes Rep 2013; 2:315-9.

23. Neves JA, Zangirolani LTO, Medeiros MAT. Avaliação do atendimento nutricional de adultos com excesso de peso na perspectiva da atenção integral à saúde. Rev Nutr 2017; 30:511-24.
24. Assis CN. Práticas de cuidado às pessoas com excesso de peso no Sistema Saúde: onde ficam os sujeitos e a subjetividade? [Dissertação de Mestrado]. Rio de Janeiro: Universidade do Estado do Rio de Janeiro; 2017.

25. Teixeira FV, Pais-Ribeiro JL, Maia AC. Beliefs and practices of healthcare providers regarding obesity: a systematic review. Rev Assoc Med Bras 2012; 58:254-62.

26. Teixeira FV, Pais-Ribeiro JL, Maia AC. Uns desistem, outros insistem: semelhanças e diferenças no discurso de profissionais de saúde face à obesidade. Revista Portuguesa de Saúde Pública 2015; 33:137-47.

27. Waddell JM. Improving obesity management in primary care [Tese de Doutorado]. Pittsburgh: Pittsburgh State University; 2017.

28. Budd GM, Mariotti M, Graff D, Falkenstein K. Health care professionals' attitudes about obesity: an integrative review. Appl Nurs Res 2011; 24:127-37.

29. Teixeira FV, Pais-Ribeiro JL, Maia AC. Different settings, different approaches: a qualitative comparison of Portuguese dietitians' beliefs, attitudes and practices about obesity in public and private settings. Public Health Nutr 2018; 21:435-46.

30. Swinburn B, Kraak VI, Allender S, Atkins VJ, Baker PI, Bogard JR, Brinsden H, et al. The global syndemic of obesity, undernutrition, and climate change: The Lancet Commission report. Lancet 2019; 393:791-846.

31. Zheng A, Cretikos M. How can health services strengthen support for children affected by overweight and obesity, and their families? Public Health Res Pract 2019; 29:e2911903.

32. Ministério da Saúde; Organização Pan-Americana da Saúde. Perspectivas e desafios no cuidado às pessoas com obesidade no SUS: resultados do Laboratório de Inovação no manejo da obesidade nas Redes de Atenção à Saúde. Brasília: Ministério da Saúde; 2014.

33. Subsecretaria de Atenção à Saúde; Subsecretaria de Vigilância em Saúde, Secretaria de Estado de Saúde do Rio de Janeiro. Plano de ações estratégicas para o enfrentamento das doenças crônicas não transmissíveis (DCNTs) no Estado do Rio de Janeiro, 2013-2022. Rio de Janeiro: Secretaria de Estado de Saúde do Rio de Janeiro; 2012.

34. Ministério da Saúde. Organização regional da linha de cuidado do sobrepeso e obesidade na rede de atenção à saúde das pessoas com doenças crônicas. Brasília: Ministério da Saúde; 2014. 
Abstract

Brazil has developed policies for the prevention and control of obesity through the Brazilian Unified National Health System. This study analyzed the characteristics of proposed "models of care" reported by health professionals in primary care in the state of Rio de Janeiro. The methods included interviews and focus groups with professionals and managers in primary care and the thematic areas of food and nutrition in the 92 municipalities (counties) of Rio de Janeiro state and document analysis of federal and state legislation and guidelines. The analysis was oriented by the organizational and technical dimensions of care and the principles of comprehensive healthcare. The main challenges reported by health professionals pertained to adherence to the therapeutic process and feelings of frustration and powerlessness; multidisciplinary teamwork; and unpreparedness for dealing with the complexity of the health-disease process related to obesity. Some principles and guidelines based on the government policy documents are strategic for addressing these challenges, especially: shared responsibility between health professionals and users, which can help avoid the extremes of blaming and/or victimization; appreciation of other gains besides weight loss, which can redefine treatment adherence; and multidisciplinary teamwork to develop a contextualized understanding of the health-disease process and its multiple conditioning factors and for the health professionals to be able to cope with their own feelings and stigmas towards the person with obesity.

Promary Health Care; Obesity; Delivery of Health Care; Integrality in Health

\section{Resumen}

Brasil ha estado instaurando politicas de prevención y control de la obesidad mediante el Sistema Único de Salud. Este estudio analizó las características de los "modelos asistenciales" propuestos y referidos por profesionales de la atención básica en el Estado de Río de Janeiro. Los métodos incluyeron entrevistas y grupos focales con profesionales y gestores de la atención básica y de las Áreas Técnicas de Alimentación y Nutrición (ATAN) de 92 municipios del Río de Janeiro, así como el análisis documental de normativas federales y estatales. El análisis consideró la dimensión organizativa y técnica asistencial, así como los principios de la Atención Integral en Salud. Los principales desafíos señalados por los profesionales se relacionan con: adhesión a los procesos terapéuticos y consecuente sentimiento de frustración e impotencia; actuación en un equipo multiprofesional; constatación de la poca preparación para enfrentarse a la complejidad del proceso salud-enfermedad relacionado con la obesidad. Algunos principios y directrices pautados en los documentos de políticas gubernamentales son estratégicos para enfrentar estos desafios, especialmente: la corresponsabilización entre el profesional y usuario, puesto que puede contribuir a evitar los extremos de culpabilización y/o victimización; la valoración de otros beneficios -además de la pérdida de peso-, que pueda volver a dar un significado a la concepción de adhesion al tratamiento; la actuación multiprofesional para que se desarrolle una comprensión contextualizada del proceso salud-enfermedad y sus múltiples condicionantes, con el fin de que los profesionales consigan enfrentarse a sus propios sentimientos $y$ estigmas referentes a las personas con obesidad.

Atención Primaria de Salude; Obesidad; Prestación de Atención de Salud; Integralidad en Salud
Recebido em 17/Mai/2019

Versão final reapresentada em 04/Ago/2019

Aprovado em 03/Set/2019 